\title{
Participatory ergonomics among female cashiers from a department store
}

\author{
María Yanire León Cristancho* \\ Unidad de Ergonomía, Facultad de Ciencias Biológicas, Universidad de Concepción, Concepción, Chile
}

\begin{abstract}
The objective of this paper was to control ergonomic risks among female cashiers working in a department store belonging to the retail market. This study was conducted between May and November 2010. Participatory ergonomics was applied through knowing and understanding how the company works, establishing the work team (Ergo group), training the team in ergonomics-related topics, and making decisions and interventions. The sample was composed of 71participants - mostly female cashiers-, and all of them have a musculoskeletal compromise, declaring pain or discomfort mainly in the neck, lower back, right wrist and shoulders. Among others, following problems were found: postural overload, repetitive work, manual load handling, mental fatigue, environmental discomfort, variable work schedules, extended working days, and absence of breaks. In the intervention, the main implemented changes were the redesign of workstation, complete change of chairs and keyboards, and the implementation of a rotation system, as well breaks for compensatory exercises. After that, an evident improvement of found problems was observed, therefore it can be concluded that participatory ergonomics is an attractive methodology, appropriate and efficient for solving and controlling ergonomic risks and problems.
\end{abstract}

Keywords: Participatory Ergonomics Intervention, Female Cashiers, Retail Market, Ergo Group.

\section{Introduction}

\subsection{Concept of participatory ergonomics}

Participatory ergonomics depart from the base that the worker knows better that anybody his own working place, allowing him to develop offers of improvement with good results [1] without the necessity of complicated technical protocols [4,5]. The definition of Participatory ergonomics of Hanes and Wilson from 1997 is the most mentioned; these authors refers to participatory ergonomics as "a strategy to involve the persons in the planning and control of a significant part of his work, with the sufficient knowledge and power to influence the processes and their results with the aim to obtain desirable goals [4-6].

Nowadays Canada, United Kingdom, Holland and Finland are the countries recognized for the use of participatory ergonomics [3]

The participatory ergonomics in Chile is in an initial stage, which principal interventions have developed in the mining industry, being out lined an important program carried out in the Chuquicamata division of the Copper Corporation of Chile, CODELCO [1].

\subsection{Classification of the participatory interventions}

Interventions based on the participatory ergonomics can be classified as "Micro" interventions or "Macro" intervention, that is to say, punctual interventions in the working place that take as an object the redesign of the same one, or interventions that take as an object the set of the organization of the work [4].

The participatory interventions can be permanent when they join the structure of the organization and temporary when they are used for specific actions [5].

\subsection{Participatory process of intervention}

According to Gadea, the process of intervention is in the habit of being systematic and consists of [5, 7]:

1. Preparation, organization and formation of the group of intervention.

2. Analysis of the problem.

*Corresponding author. E-mail: yanireleonft@hotmail.com 
3. Search and selection of solutions with the method of Brainstorming.

4. Implementation of the solutions.

5. Evaluation of the results.

\subsection{Advantages of the participatory ergonomics}

The advantages of the participatory ergonomics according to Gadea, Darses and Reuzeau are [3, 4]:

- Efficiency of the implemented changes. The workers accept better the changes in which they were involved, than that in those taxes for the hierarchic structure.

- Improves the production, even if the advance of the safety and the conditions of work continue in process.

- Helps in the development of the competitions of the persons and of the company.

- Contributes to the generation of confidence feelings and self-esteem.

- Provides satisfaction in the work.

- Improves the cohesion of the organization.

\subsection{Obstacles in the participatory ergonomics}

According to Gadea, the principal obstacles that they present in the use of ergonomics are [4]:

- Effort needed to motivate the participants.

- Investment of time and money.

- Emergence of conflicts in the different levels of the organization.

- Generated unsatisfied Expectations.

-

1.6. Recommendations to facilitate the use of the participatory ergonomics

There does not exist only one method of participatory ergonomics, but the following tools, according to Hignett, Darses, Reuzeau and García, can facilitate his realization $[3,4,6]$ :

- To do a rapid initial consideration of the magnitude and general characteristics of the problems, the predictable obstacles in the development of the methodology, the load of work and the global impact of the participation.

- To previously identify the voluntary members of the participative group, the aims of his participation, the level of participation and the participative methods to use.

- To favor the participation of workers, supervisors and executives.
- To involve experts and beginners, because both develop mental models and different behaviors in the accomplishment of his work.

- The members must have communicative and explanatory capacities in order to facilitate the process of participation.

- To distribute tasks depending on the knowledge, skills, and availability of the members.

- To continue systematically the stepwise, doing adjustments according to the obtained results.

- To provide to the workgroup the necessary information for the exercise of his judgment.

- To dictate rules that guarantees the commitment of the persons.

- To use understandable vocabulary that allows the exchange of knowledge.

\subsection{Ergo group}

The Ergo Group is the central element of the participatory ergonomics [7]. It is a committee of work that assembles, in the company persons who have competences and different points of view, with the aim to identify and anticipate factors of risk. In general it is constituted by groups from 4 to 8 persons that occasionally incorporate persons related to the problem that is investigated. This group must qualify, at least, in general knowledge of ergonomics, methods and tools of ergonomic analysis and solution of problems. The above mentioned knowledge can be acquired in the measure that they could need in the course of the work [4].

\subsection{Functions of the ergonomist in a participatory methodology}

There corresponds to the ergonomist, the construction of the participative action, his follow-up and the analysis of the information with the different participants [3]. Therefore, it needs to confront the members of the Ergo Group, to link the information with the procedure and available rules, to solve the conflicts, construct the necessary expedient for the taking of decisions, prepare ergonomic recommendations, to make sure itself of the commitment of all the actors, to choose the participants, the methods and tools, to apply the participation methods, to accompany the dialog and to lead the mediation, among other functions. 


\subsection{Precedents of the studied company}

During the first semester of 2010 an ergonomic study was realized in the cashiers of the store selected for this study, leading company in materials for the construction and articles for the home. In this store, $58,8 \%$ of the Work accidents and Occupational diseases had commitment Skeletal-Muscle [2]. These injuries were compromising $100 \%$ of the cashiers, who were demonstrating pain or discomfort principally in the neck, lumbar region, right wrist and shoulders. These disorders caused that $40 \%$ of the cashiers had license at any time of his labor history. The cashiers of this store realized their principal activity (to charge) during $63 \%$ of the day and the only pause (to have lunch) was corresponding to $12 \%$. The actual activities of the post were executing them principally in seated position, in chairs in bad conditions and without ergonomic criteria, in front of monitors located over the line of vision, with printers far from their scope, realizing the same pattern of movement during $63 \%$ of the day. These cashiers were attending to 23 clients per hour, with a duration of 1,8 minutes for client and five seconds for product (to take the product, to remove the alarm, to orientate the bar code towards the scanner and to give up the product), they were raising even $20 \mathrm{Kg}$ in a standing position and up to $6,5 \mathrm{Kg}$ in sat position because of the lack of rolling tape in the equipment.

The mental load of the cashiers was given by the high pace of work, the simultaneous visual and auditory information, the rapid response to the imponderables, the lateness of the supervisor, the constant manipulation of different forms of payment, the relation with the clients, the long journeys (10 at 12 hours), the absence of rotation of functions, the variable schedules, the lack of programmed pauses and the exigency of memorizing (codes of products, location of products in the corridors, offers and functions of the keys).

The cashiers were exposed to cold in winter and to heat in summer, to noise-51 to $105 \mathrm{~dB}(\mathrm{~A})$ - from the service of rental (the testing of tools), the magnifying of sounds and, to reflections in the monitors for his inadequate location regarding to lights and doors.

With the purpose of controlling the problems previously mentioned, there arose the idea of using the participatory ergonomics, taking advantage of its advantages $[3,4]$.

\section{Method}

\subsection{Participants}

The sample was composed of 71 participants, in the main, cashiers of a great company of the sector of the retail (Table 1 and Table 2).

Table 1

Composition of the sample

1 Chief of human resources
1 Chief of prevention of losses
1 Sub manager of operations
1 Engineer in prevention of risks
1 Chairwoman of the Equal Committee
10 Supervisors
56 Cashiers

Table 2

Composition of the sample according to the proposed activity

\begin{tabular}{ll}
\hline Ergo Group & $8^{*}$ \\
Survey of satisfaction & 56 cashiers \\
Trainings & 10 supervisors \\
\hline
\end{tabular}

*Chief of Human Resources, Chief of Prevention of Losses, Sub manager of Operations, Engineer of prevention of Risks, Chairwoman of the Equal Committee of Labor Security and Occupational Health, Supervisor of cashiers, two Cashiers.

This work was realized between June and December, 2010. For his development a systematic process was followed, it consisted in: bibliographical review on participatory ergonomics, knowledge and understanding of the system of functioning of the store, constitution and training of the Ergo group and, finally, accomplishment of ergonomic interventions with the joint effort of the group Ergo.

The knowledge and understanding of the system of functioning of the store was achieved by visits of inspection and observation to the company, as well as by formal and informal interviews to executives and workers of the store. And there was realized an analysis of photographic record and of video.

The constitution of the Ergo group was realized systematically: first there was realized a list of persons that to criterion of the person in charge of the project, they would be key for the success of the participatory activity and for the ergonomic interventions. To these persons there were announced the aims and the scopes of the project, seeking to motivate them to take part in the group; later they signed accepting the voluntary entail and the commitment to invest time and energy. 
The training of the participatory group was developed in the facilities of the store, in rooms destined for meetings and activities of formation, by means of theoretical - practical meetings, with a maximum of two hours each, and the use of didactic technologies and the delivery of supporting material. During every session they presented the results of the ergonomic evaluation realized before, which was confronted with the law and literature. The topics raised in the different meetings were: "Design of the Working Station and Postural Overload", "Repetitive Work and Muscle-Skeletal Disorders", "Manual Managing of Loads", "Noise, Thermal and Lighting Discomfort", "Work Journeys and Pauses" and, "Benefits of Physical Exercise". To conclude each session there were developed a discussion based on the ergonomic recommendations and on the new proposals that were arising from the group. At the end of every session the interventions were remaining definite to implement within a short, medium and long term. The ergonomic short-term interventions were realized immediately finished every training, before the following session.

\section{Results}

\subsection{Knowledge and understanding of the} system of the store

The store belongs to a chain of stores which administration is centralized in the capital of the country (Santiago). The internal organization of the store has a vertical structure, with six clearly identified lines: 1. Manager of the store. 2. Chief of human resources and chief of prevention of losses. 3. Sub managers of operations, home, tool store and court. 4. Chiefs of sales department. 5. Supervisors. 6. Sellers and cashiers.

As consequence of the centralization and the vertical organization of the company, the changes and the acquisition of elements are generalized for every store, the acquisition is limited to an annual budget, the solution of problems is delayed on having needed authorization of several levels and the workers do not take part in any project of the company.

With base to the distribution of the store, two important aspects are outlined: Service of rental as the source of noise and, the location of the boxes versus the gondolas as a source of different biomechanical risks. Boxes opposite to gondolas with home products (small and light), whose principal factor of risk is the repetitiveness. Boxes opposite to gondolas with products for the construction (voluminous and heavy) that promote the displacement of the cashiers towards the products.

The principal problem of commercialization and provision of services becomes evident in the boxes, where the process slows down because of the delay during clients' attention. It is important to indicate that the delays do not depend only on the box sections but on the previous stages: Reception must deposit the products to the system of the shop and assign a code to the products that come without this one. To the Systems corresponds to audit the functions of receipt and to change the prices according to the promotions. Sales, it checks that the products that the client takes to himself have the respective visible bar code.

The principal reasons of the delays in the attention to clients are: products that come to boxes with bar codes that are not read because the labels are not in good condition (It increases the number of times of scanning and later it is needed to digit), products without bar code (it needs to call to the department in charge of the product, look for the support of a supervisor and to rig), products that come to boxes with bar codes that can not be read because they have not been deposited in the system, products which price is different from the exhibited one in the gondolas because it has not been modified in the system (it requires to call to the department in charge of the product and to look for the support of a supervisor) and deficient communication between the cashier and the supervisor, because when the cashier needs the support of the supervisor, it comes vociferously and pointing because of the lack of other means (radiotelephone, visual alarms).

The principal problems of the cashiers' organization of the work are assumed to a variability in the schedules, long journeys of work (10 at 12 hours per day), absence of rotation of functions, absence of a system of pauses (the only pause is an hour for lunch) and absence of programs of maintenance and repair. On the other hand, the cashiers do not reach the incentives and the salaries range between 120.000 and 260.000 Chilean pesos.

The products of use of the cashiers did not have ergonomic criteria because in the store they were prioritizing the economic criteria. In the products that the store commercializes the ergonomic criteria is not highlighted: this one would be a competitive advantage. 


\subsection{Constitution Ergo group of the store.}

The Ergo group of the store was constituted by 8 workers and an expert ergonomist. Since representatives of the company took part: The Chief of Human Resources, Chief of Prevention of Losses, Sub manager of Operations and Chairwoman of the Equal Committee of Occupational Health; as representatives of the workers: a Supervisor, two Cashiers and an engineer of prevention of Risks. There were incorporated in occasional form persons directly related to the problems that in the moment were being intervened, as the Manager of the Store and the Manager of Maintenance.

\subsection{Training of the Ergo group}

The participation in the training meetings fluctuated according to the needs and events of the company. The high controls received $83 \%$ of the trainings; Cashiers, Supervisor and the engineer of prevention of risks had major participation in the trainings (Graph 1); and better assistance was obtained during the development of the first topics (Graph 2).

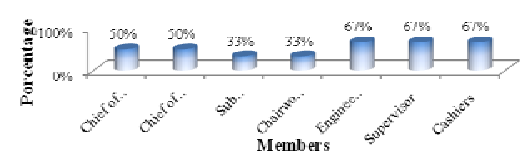

Graph 1 - Percentage of the participation of the members of the ERGO group in the trainings

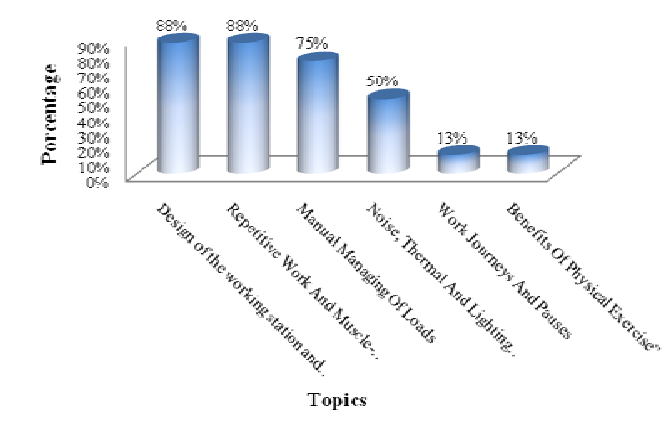

Graph 2 - Percentage of assistance according to the subject matters exposed in the trainings

\subsection{Ergonomic interventions}

After developed the training "Design of the working station and postural overload", with the respective discussion between the members of the Ergo group and the maintenance manager, it is decided to remove the base of the monitor in order that this one stays to the eye-soil height, between 5 and 95 percentile of the cashiers and to cut a booth of wood where there was located the printer of factures that was producing postural overload to the shoulder. First a pilot test was done by two stations, later it was implemented on all the stations because the survey of perception threw $100 \%$ of acceptance in the cashiers. In the Figure 1 the stations appear before and after the changes. In the Figure 2 the relation place of work cashier is observed before and later the interventions and in the Table 3 the anthropometrics measures and the dimensions of the working place.

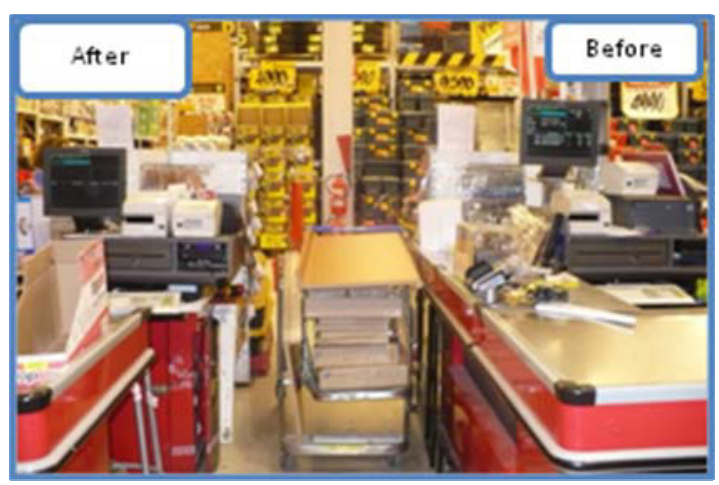

Figure 1 - Station of boxes before and after the changes 


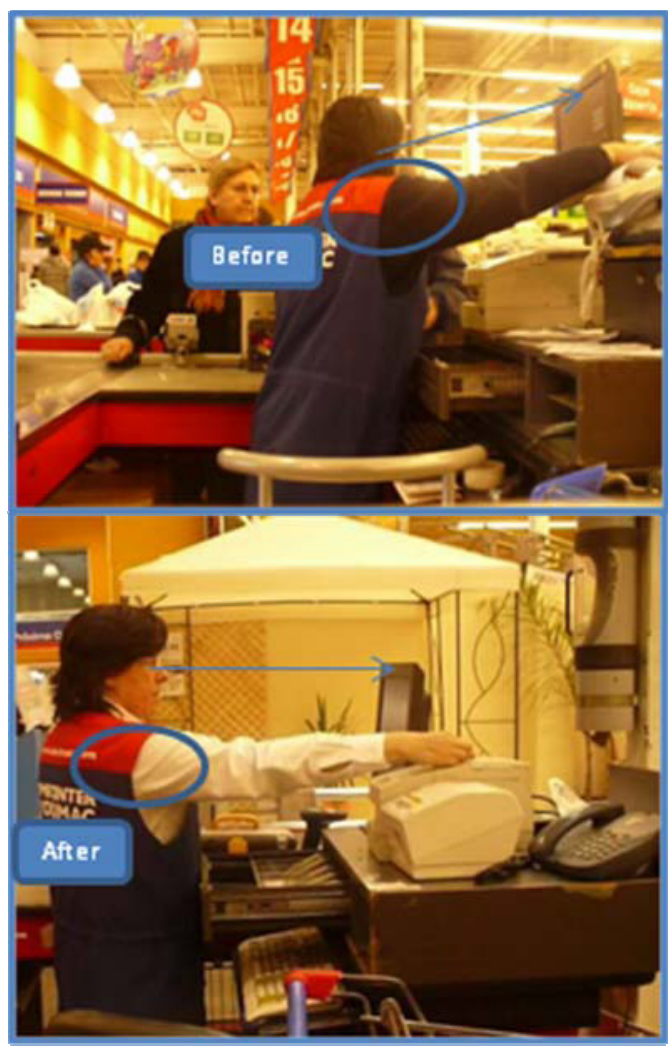

Figure 2 - Relation place of work - cashier before and after the interventions

Table 3

Anthropometry of the evaluated cashiers and dimensions of the working place

\begin{tabular}{|c|c|c|c|}
\hline Monitor height & \multicolumn{2}{|c|}{ Printer height } & \multirow[t]{2}{*}{5 and 95 percentile } \\
\hline Before After & Before & After & \\
\hline $167,5 \quad 145$ & --- & --- & $\begin{array}{c}\text { Distance eye-floor } \\
139,9-158,36\end{array}$ \\
\hline--- & 138 & 122 & $\begin{array}{c}\text { Distance elbow-floor } \\
94,79-109,74\end{array}$ \\
\hline
\end{tabular}

The measures are expressed in centimeters.

The Ergo group achieves that the company changes the totality of the chairs of the cashiers. Figure 3 shows the chairs that were in use versus the new ones. The previous chairs were in poor condition and without ergonomic conditions. Though the new chair does not accomplish with all the ergonomic criteria, it is a good advance. A rotation system is implemented between boxes where small and light products and boxes where voluminous and heavy products pass through. The rotation takes place at the middle of the journey, taking advantage of the lunch pause. The system of active pauses is implemented in the middle of the morning and middle afternoon. Ten supervisors of the store were qualified and possess a guide of support to direct the compensatory exercises.

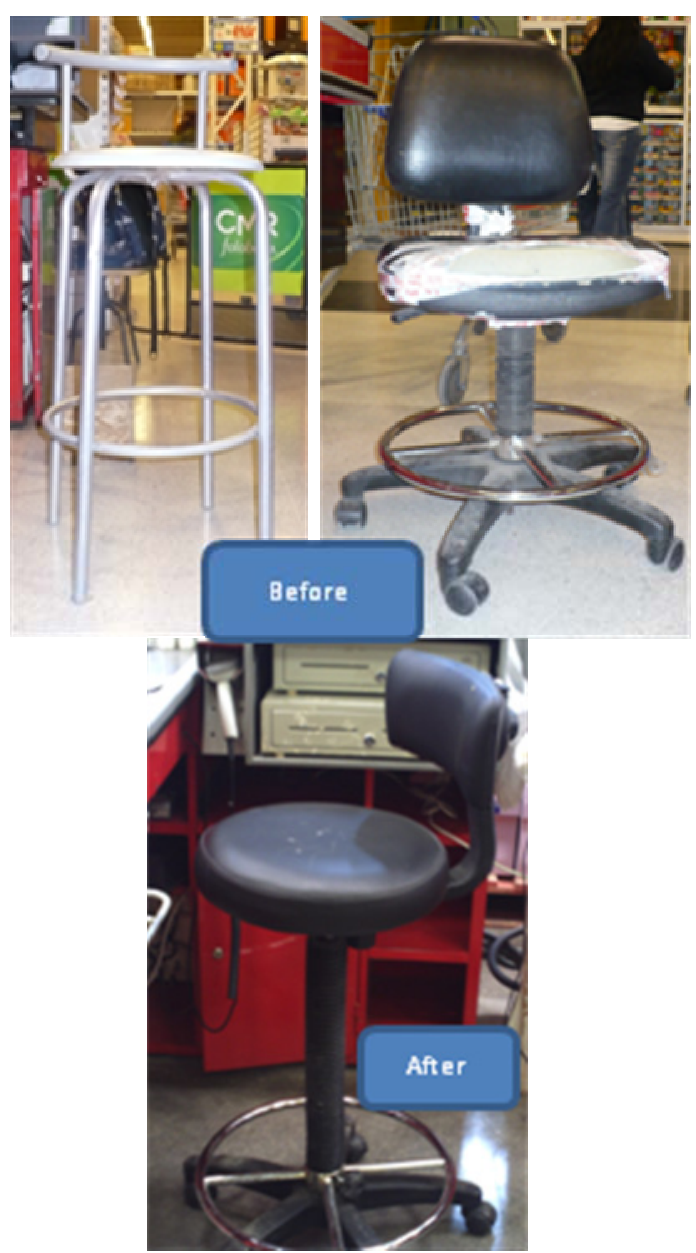

Figure 3 - The Chairs of the cashiers before and after the interventions

\section{Conclusions}

The participatory ergonomics are a valuable tool that helps to go out from the diagnosis to control, as it was for the cashiers of the store.

The methodology allows constructing mutually and it requires a collective learning and is the product of a voluntary commitment that forces the participants to change their habitual manners of work [3]; this was observed in the members of the Ergo group of the store

Before implementing the participation it is recommended to plan bearing the aims to reach in mind, 
selecting and conquering the key persons inside the organization in order that they take part in the Ergo group, to arouse managers and other high controls of the benefits of using participatory ergonomics inside the company: by these means they promote and facilitate the intervention.

The ergonomist is the mediator during the whole participatory process, the one who must facilitate the construction of ergonomic ideas, but never impose personal points of view; this way, the group appropriates the ideas and works up to achieve the changes, and it must not create false expectations, making know to workers that they contribute the ideas that will be evaluated by the specialists. The good attitude and the professionalism of the ergonomist favor the approximation to the company and the collaboration of all the involved persons.

\section{References}

[1] B. Apud E, Meyer F. Cap. 6. En: Apud E, Meyer F. Ergonomía para la industria minera. Concepción, Chile: Universidad de Concepción, CODELCO. 2009. p.429-432.

Asociación Chilena de Seguridad. Anuario Estadístico. Santiago: ACHS. 2010.

[2] Darses F, Reuzeau F. Participación de los usuarios en el diseño de los sistemas y dispositivos de trabajo. En: Fundación MAPFRE. Manual de ergonomía. $1^{\mathrm{a}}$ ed. Madrid, España: Modus Laborando. 2009. p. 411-427.

[4] Gadea R. ¿Qué es la ergonomía participativa? IS TAS [en línea]. Abr. 2008;(40). Disponible en: http://www.istas.net/pe/articulo.asp?num=40\&pag=10\&titulo $=-$ Que-es-la-ergonomia-participativa- [Consultado en enero2009].

[5] García A, Gadea R, Sevilla M, Genís S, Ronda E. Ergonomía participativa: empoderamiento de los trabajadores para la prevención de trastornos músculo-esqueléticos. Rev Esp Salud Pública [en línea]. Jul. - Ago. 2009; 83(4): 509-518. Disponible

http://redalyc.uaemex.mxpdf/170/17011699003.pdf [Consultado en enero 2009].

[6] Hignett S, Wilson JR, Morris W. Finding ergonomic solutions-participatory approaches. Occup Med 2005; 55: 200207.

[7] St-Vincent M, Chicoine D, Simoneau S. 1998. Les groupes ERGO: un outil pour prevenir les LATR. Québec: Institut de Recherche en Santé et Sécurité du Travai; 1998. 